\title{
FINITE ELEMENT ANALYSIS OF PEDAL POWER HUB DYNAMO
}

\author{
Vivek Kumar $^{1}$, Dr. Prakash Verma ${ }^{2}$ \\ ${ }^{\mathbf{1}}$ Research scholar (Machine Design), ${ }^{\mathbf{2}}$ Professor, \\ ${ }^{1,2}$ Department of Mechanical Engineering, Jabalpur Engineering College, Jabalpur (MP), \\ India
}

\section{ABSTRACT:}

The Hub Dynamos are built for electricity generation form the bicycle motion and they are in light weight and have low frictional resistance. However they are still subjected to normal bicycle loading such as bicycle frame, rider weight, acceleration, braking and cornering forces. The challenge is to develop a lightweight hub housing and hub axle that can safely withstand the required loads. The present paper deals with designing a Hub dynamo assembly using Solid Works Office Premium software. The assembly comprises of the Hub shell, hub axle, internal gear assembly, armature, and fasters. Static structural analysis was done using $S W$ simulation software. The plots for equivalent von-misesstress plot, total deformation plot were obtained and the design was continuously optimized till a safe design was obtained.Maximum distortion energy theory was used for the analysis. The material assignment is as follows: hub assembly- Aluminum Alloys 356.0 T-6, hub axle- ASTM A36 Steel and Gear Assembly Bracket-Alloy Steel (SS).

\section{KEYWORDS:}

Solid works simulation, Finite Element Analysis, Hub Dynamo, Hub Axle.

\section{INTRODUCTION:}

Finite element method is one of the most acceptable and is easily integrated into the computeraided engineering environment. Solid-modeling CAD software like (Solidworks, Creo, Catia, UgNx etc.) provides an excellent platform for the creation of FEA models. Through solid modelling, the component is described to the computer and this description affords sufficient geometric data for construction of mesh for finite element modelling. Purohit and Sagar (2005-2006) have done the finite element analysis of Al-SiCpvalve seat inserts and composite poppet valve guides. Purohitet. al. (2010) have done the finite element linear static analysis of motorcycle piston.A hub dynamo is a small electrical generator built into the hub of a bicycle wheel that is usually used to power lights. In the present work a Hub dynamo assembly has been designed in the Solid Works Office Premium Software. Thereafter, static structural analysis of some part was done. The assembly consists of an axel, Hub shell, Gear assembly bracket and a magnet holder.

\subsection{Hub shell}

A hub is the center part of a bicycle wheel. It consists of bearing 6000rs, an axle, and a hub shell. The hub shell typically has two machined metal flanges to which the spokes can be attached. 


\subsection{Hub Axle}

The hub axle is attached to dropouts on the fork or the bicycle frame. Modern bicycles have adopted standard axle spacing: the front wheels hub are generally $100 \mathrm{~mm}$ wide fork spacing, road wheels with freehubs (rear wheel hubs) generally have a $140 \mathrm{~mm}$ wide, which allows clearance to mount free wheel, a brake disc on the hub or to decrease the wheel for a more durable wheel.

There are two major part that are subjected to normal bicycle loading such as bicycle frame, rider weight, acceleration, braking and cornering forces. Other part of hub dynamo are armature assembly, magnet, magnet holder, gear assembly, nuts and bearings etc.

\section{STATIC STRUCTURAL ANALYSIS}

\subsection{Equivalent Stress (Von-Mises Stress)}

While the Equivalent Stress at a point does not uniquely define the state of stress at that point, it provides adequate information to assess the safety of the design for many ductile materials. It states that inelastic action at any point in a body, under any combination of stress begins, when the strain energy of distortion per unit volume absorbed at the point is equal to the strain energy of distortion absorbed per unit volume at any points in a body stressed to the elastic limit under the state of uniaxial stress as occurs in a simple tension/compression test.

Equivalent stress is related to the principal stresses by the equation:

$$
(\mathrm{S} 1-\mathrm{S} 2)^{2}+(\mathrm{S} 2-\mathrm{S} 3)^{2}+(\mathrm{S} 3-\mathrm{S} 1)^{2}=2 \mathrm{Se}^{2}
$$

Distortion energy theory is used in design work because it allows any arbitrary three-dimensional stress state to be represented as a single positive stress value. It cannot be applied for material under hydrostatic pressure. Equivalent stress is part of the maximum shear stress energy theory used to predict yielding in a ductile material.

\subsection{Total Deformation}

The applied external loads on a body are transmitted to the support through the material of the body. This phenomenon tends to deform the body. The deformation of a part under a load is proportional to its length. Deformation is calculated relative to the part or assembly in coordinate system.

$$
\mathrm{U}^{2}=\left(\mathrm{Ux}^{2}+\mathrm{Uy}^{2}+\mathrm{Uz}^{2}\right)
$$

Ux, Uy and Uz are the three components of Deformation. 


\subsection{Stress tool (Factor of safety)}

In simple systems only one kind of stress is easy to anticipate the failure, but in complex stress systems in which direct as well as shear stresses act, it is not easy to do so. The following factor of safety tools are available to design the safe strength of the object:

1. Maximum Equivalent Stress Safety Tool

2. Maximum Shear Stress Safety Tool

3. Mohr-Coulomb Stress Safety Tool

4. Maximum Tensile Stress Safety Tool

In the present analysis Maximum Equivalent Stress Safety Tool has been used. The Maximum Equivalent Stress Safety tool is based on the maximum shear strain energy theory for ductile materials, also referred to as the Mises' and Hencky's theory, or maximum distortion energy theory (or shear strain). Out of the four failure theories supported by Simulation, this theory gives most appropriate result when applied to ductile materials such as aluminum, brass and steel. As shear stress and shear strain energy theories depend upon the stress differences, a material has no chance of failure if the principal stresses are the same nature (tensile or compressive) and the magnitude since the difference will be negligible. Thus these theories should not be applies when the material under hydrostatic pressure.

The theory states that the failure takes place when the shear strain energy in a complex system becomes equal or exceeds to that in simple tension.

$\mathrm{Se} \geq$ Slimit

Expressing the theory as a design goal:

Se / Slimit $<1$

If failure is defined by material yielding, it follows that the design goal is to limit the maximum equivalent stress to be less than the yield strength of the material:

$\mathrm{Se} / \mathrm{Sy}<1$

The fracture occurs when the maximum equivalent stress of the material reaches or exceeds the ultimate strength of the material:

$\mathrm{Se} / \mathrm{Su}<1$

Safety FactorFs $=$ Slimit $/$ Se.

Using the Equivalent Stress (Von Mises Stress), the Total Deformation and the Stress Tools; it was determined whether the parts would yield under loading conditions or not.

\subsection{Design Considerations}

A pedal power hub dynamo of good design must have adequate torque capacity, dynamic loading, shock loading, and ability to withstand and dissipate heat and should have a long life. The hub dynamo must have smooth engagement, low operating force and ease of repair. To overcome the torque, dynamic and shock loads on the driven parts, when starting, hub dynamo should be designed for overload capacities of 75 to 100 percent. 


\section{FINITE ELEMENT ANALYSIS OF HUB DYNAMO ASSEMBLY}

The finite element analysis of hub dynamo assembly was carried out in the following steps:

1. Calculation of the dimensions of the hub dynamo assembly

2. Material selection for the hub, hub axle, magnet holder, and gear train

3. Creating a three-dimensional model of hub dynamo assembly (hub housing, hub side cover, axle, connector assembly, wire harness, armature, magnet holder and gear train) in Solid Works Office Premium Software

4. Exporting the model for simulation and dividing it into small elements

5. Defining the material property and geometry data

6. Defining the loads and supports on the parts

7. Submitting the Model to the solver; Obtaining Solution (Equivalent von-Mises stress plot, TotalDeformation plot and Stress Tool) and evaluation of the results

\subsection{Material Selection}

The following materials were selected for finite element analysis of hub dynamo parts:

1. Hub Assembly: Aluminum Alloys 356.0 T-6

2. Hub Axle : ASTM A36 Steel

3. Gear Assy. Bracket: Alloy Steel (SS)

Table: 1 Mechanical properties of materials

\begin{tabular}{|l|l|l|l|l|}
\hline S.No. & Material Properties & $\begin{array}{l}\text { Aluminum Alloys } \\
\mathbf{3 5 6 . 0} \text { T-6 }\end{array}$ & $\begin{array}{l}\text { ASTM-A36 } \\
\text { Steel }\end{array}$ & Alloy Steel (SS) \\
\hline 1 & Elastic Modulus (N/m2) & $7.40 \mathrm{E}+10$ & $2.00 \mathrm{E}+11$ & $2.10 \mathrm{E}+11$ \\
\hline 2 & Poisson Ratio & 0.33 & 0.26 & 0.28 \\
\hline 3 & Shear Modulus (N/m2) & $2.72 \mathrm{E}+10$ & $7.93 \mathrm{E}+10$ & $7.89 \mathrm{E}+10$ \\
\hline 4 & Mass Density (Kg/m3) & 2680 & 7850 & 7700 \\
\hline 5 & Tensile Strength (N/m2) & $2.28 \mathrm{E}+08$ & $4.00 \mathrm{E}+08$ & $7.23 \mathrm{E}+08$ \\
\hline 6 & Yield Strength (N/m2) & $1.52 \mathrm{E}+08$ & $2.50 \mathrm{E}+08$ & $6.20 \mathrm{E}+08$ \\
\hline
\end{tabular}




\subsection{Development of 3-D model for Hub dynamo assembly in Solid Works Software}

It is an assembly formed from: Hub shell, Hub axle, armature, connector, internal gear train, magnet holder, and bearings 6000 rs.

1. Hub shell: The features used in Solid Works are Extrude, Cut-Extrude, Revolve, chamfer, pattern, Circular Pattern and Fillets.

2. Hub axle: The features used in Solid Works premium are Extrude boss, revolved boss, Extrude-cut, chamfer, fillets.

3. Internal Gear Train: Solid Works design library.

4. Connector: The features used in Solid Works are Extrude-boss, Extrude-cut, Revolved boss, chamfer, pattern, and Fillets

5. Bearing : Solid Works design library

6. Fasteners: Solid Works design library

Hub dynamo Assembly: Coincident, Parallel, tangent, Perpendicular, lock, distance, angularity, and concentric feature in Solid Works was used to join all components.

The figure 1 shows the finite element model of the hub dynamo assembly (Exploded View).

\subsection{Finite element analysis of each part of Hub dynamo assembly using SW simulation software}

The average speed of the bicycle is $15 \mathrm{Km} / \mathrm{h}$ for $70 \mathrm{Kg}$ person and power consumption is about 30 watts.

The RPM of the wheel (28 inches) is $111.84 \mathrm{rpm}$. The total torque on the bracket is calculate as: Wheel diameter $(\mathrm{D})=28$ inch. $=0.7112 \mathrm{~m}$

Circumference of the wheel $=\pi \mathrm{D}=22 / 7 * 0.7112=2.2352 \mathrm{~m}$

Wheel rpm $=15000 /(60 * 2.2352)=111.84 \mathrm{rpm}$

Power at the wheel is $88 \%$ of $30 \mathrm{w}=26.4 \mathrm{w}$

Then $\mathrm{T}=60 * \mathrm{P} /(2 \pi * \mathrm{rpm})$

$$
=60 * 26.4 /(6.28 * 111.84)=2.25 \mathrm{~N}-\mathrm{m}
$$

This is the average torque at the wheel for an average power of $30 \mathrm{~W}$ form the rider at the speed of $15 \mathrm{Km} / \mathrm{h}$. This is the power to overcome road friction \& drag bicycle losses at this speed. 


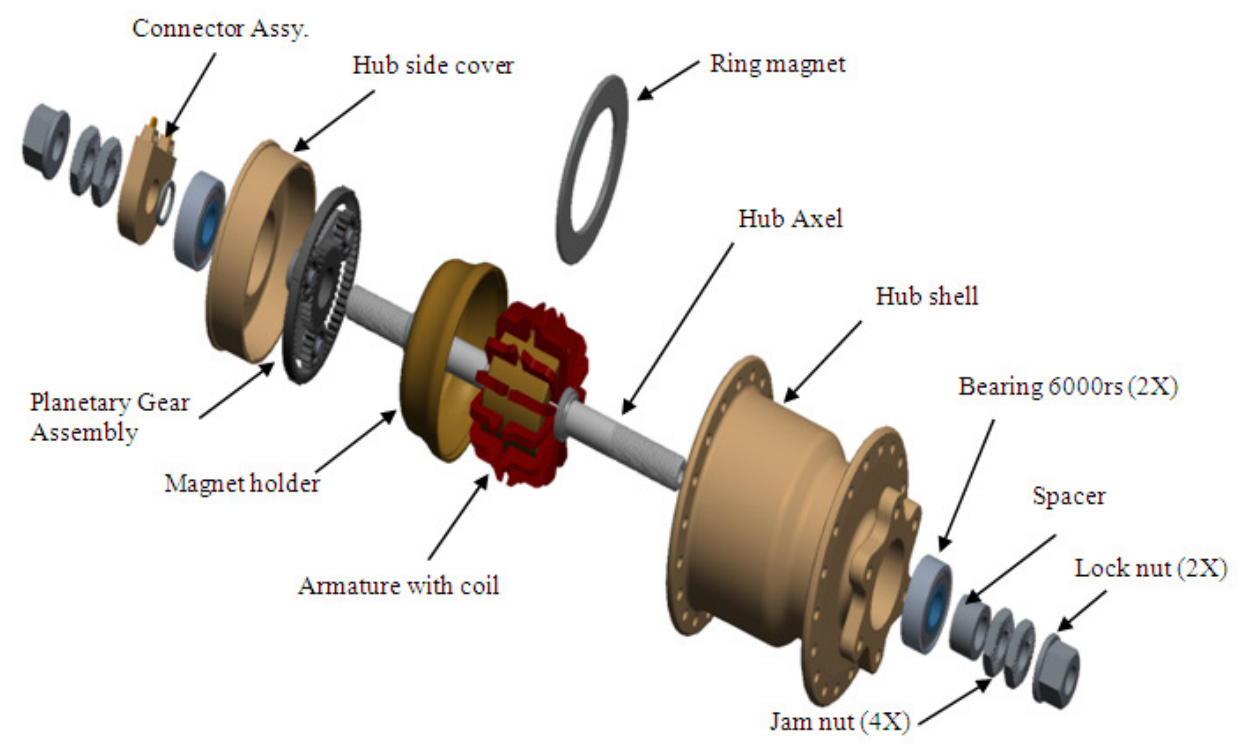

Figure. 1 Exploded view of pedal power hub dynamo

\subsubsection{Hub shell}

A hub is the center part of a bicycle wheel mounted on axle. It consists of an axle, bearings, and a hub shell. The hub shell typically has two machined metal flanges to which the spokes can be attached. Each flange has holes or slots to which spokes are affixed. The finite element analysis of hub shell follows as:

1.A Mesh was created (Dividing the hub shell into finite elements).

2.Material property of hub shellwasdefined (as per the table 1).

3.The Environment (a combination of loads and supports) was defined as follows:

Loads: Moment: $2.25 \mathrm{~N}-\mathrm{m}$ (each side);

Force: 700 Newton downwards.

The Model was submitted to the SW simulation solver and the solutions for the Equivalent vonMises stress and Total Deformation were obtained.The figure 2 shows mess and the distribution of total deformation over the hub. The figure 3 shows the distribution plot of equivalent vonMises stress over the hub assembly under the applied load condition.

Maximum Von-Mises stress (N/m2)-3.08E+06

Yield Strength $(\mathrm{N} / \mathrm{m} 2)-1.52 \mathrm{E}+08$

Total deformation (mm)-3.82E-04 
Advances in Materials Science and Engineering: An International Journal (MSEJ), Vol. 2, No. 4, December 2015
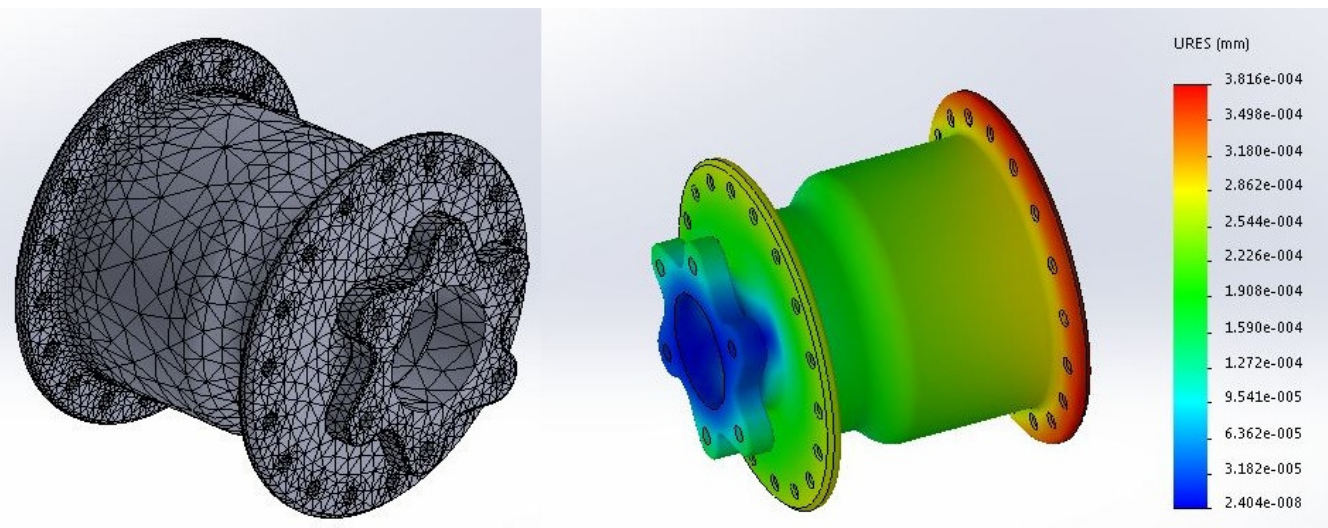

Figure: 2 Mess and Total deformation of hub shell
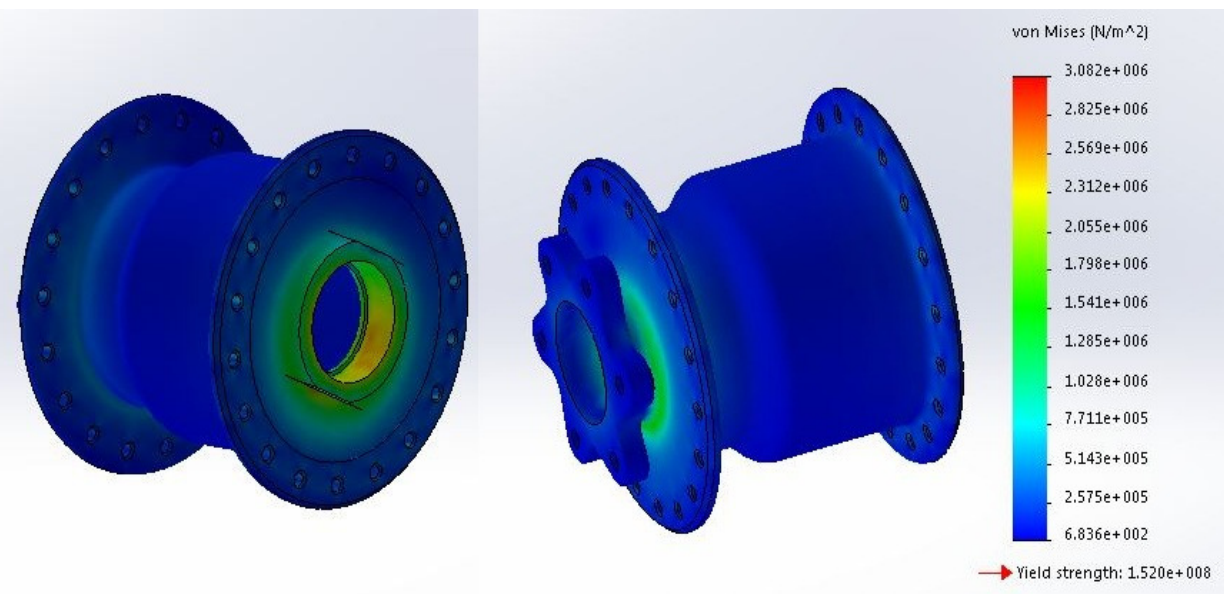

Figure: 3 the equivalent von-mises stress plot for the hub shell

\subsubsection{Gear Assembly Bracket:}

The model of the Gear Assembly Bracket was meshed. The material property of gear assembly bracketwas defined as per table 1. The Environment (a combination of loads and supports) was defined as follows:

Loads: Moment $=2.25 \mathrm{~N}-\mathrm{m}$

The Model was submitted to the SolidWorks solver and solutions were obtained (Equivalent vonMises stress and Total Deformation). The figure 4 shows mess, distribution of equivalent vonMises stress plot and total deformation over the entirebracket.

Maximum Von-Mises stress(N/m2)-1.30E+08

Yield Strength (N/m2)-6.20E+08

Total deformation (mm)-2.03E-02 
Advances in Materials Science and Engineering: An International Journal (MSEJ), Vol. 2, No. 4, December 2015
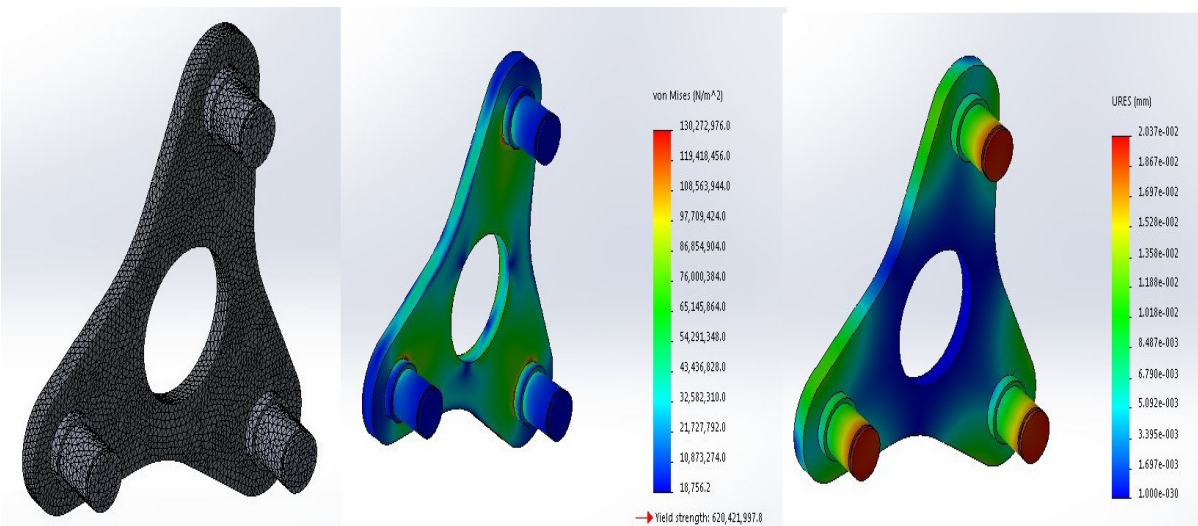

Figure: 4Mess,equivalent von-mises stress and Total deformation plot of Gear Assembly Bracket

\subsubsection{Hub Axle:}

The model of the Hub Axle was meshed. The material property was defined as per table 1 . The Environment (a combination of loads and supports) was defined as follows:

Loads: Force $=1000 \mathrm{~N}$

The Model was submitted to the SW solver and solutions were obtained (Equivalent von-Mises stress and Total Deformation).The figure 5 shows the distribution of equivalent von-Mises stress and total deformation over the entireHub axle.

Maximum Von-Mises stress (N/m2)-8.67E+07

Yield Strength (N/m2)-2.50E+08

Total deformation (mm)-9.19E-03
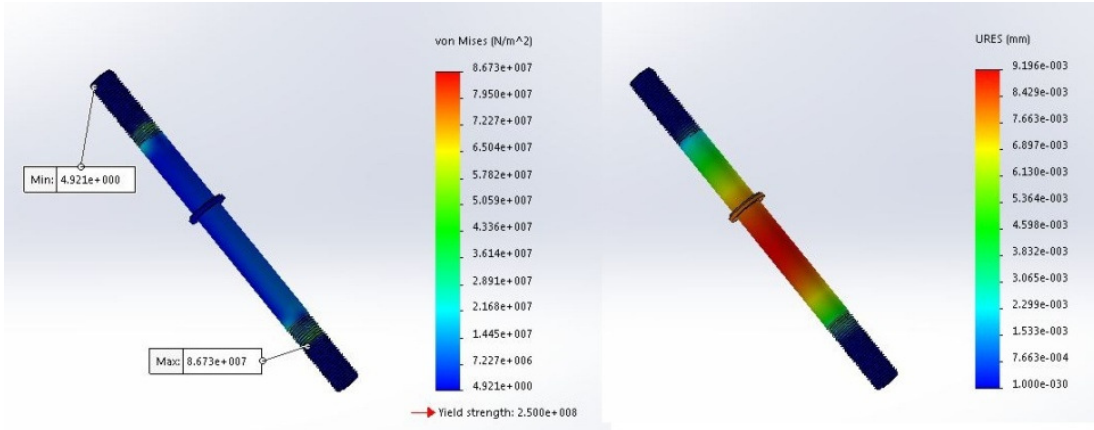

Figure: 5The equivalent von-mises stress and Total deformation plot of hub axle 


\section{CONCLUSIONS}

In the present work a hub dynamo assembly was designed and a model of the same was created in Solid Works Office Premium Software. Finite element analysis was performed in SW simulation software. The finite element analysis of hub dynamo was carried out in three steps: Preprocessing, Solving and Post processing. The plots for Equivalent von-Mises stress, total deformation were calculated and analyzed. As the maximum amplitude during FEA von-mises stress are far away than the material yield strength and there is no chance of structural damage during operation. The finite element analysis showed that the designed hub dynamoassembly is safe.

\section{References:}

[1] R.Purohit and R. Sagar, 2005 "Finite element analysis of Al-SiCp composite Poppet Valve Guide" International Mobility Engineering Congress and Exposition, SAE INDIA, Chennai.

[2] GaoLian-hua, Jia Xia-Ping, 1993 "The Structure of a Tank EM.Beiing" Academy of Armored Forces Engineering Press

[3] R.Purohit and R. Sagar, 2006 "Finite element analysis of Al-SiCp composite Valve Seat Inserts" Proceeding of National Conference on Advances in Mechanical Engineering, JamiaMilliaIslamia, New Delhi.

[4] Maha N. Haji, Kimberly Lau, and Alice M. Agogino (2010) "Human Power Generation in Fitness Facilities," Proceedings of ASME 2010 4th International Conference on Energy Sustainability ES2010.

[5] Cyders, T. and Kremer, G. G., 2008 "Engineering Around the World: Driving Local Economics in Africa with Human Power," Proceedings of the ASME 2008 International Mechanical Engineering Congress and Exposition (IMECE2008), Vol. 9: Engineering Education and Professional Development, pp. 181-187.

[6] Jansen, A. and Stevels, 2006 "Combining eco-design and user benefits from human powered energy systems, a winwin,” Journal of Cleaner Production, 14 (15-16), pp. 1299-1306.

[7] Japanese Industrial Standard, JIS C 9502: 2008 (E), Lighting equipment for bicycles.

[8] Japanese Industrial Standard, JIS D 9419: 1996 Bicycle hubs.

[9] Indian Standard, IS 629 -1988: Bicycle Hub.

[10] P. Khitoliya, DK Koli, 2014 "Design and Finite Element Analysis of an Automotive Clutch Assembly" Procedia Materials Science 490-502.

[11] MohdHanif Mat, Amir Radzi, 2012 "Design and Analysis of 'Eco' Car Chassis" International Symposium on Robotics and Intelligent Sensors.

[12] Manoj A. Kumbhalkar, DV.Bhope 2014 "Material and Stress Analysis of Railroad Vehicle Suspension: A Failure Investigation”International Conference on Nanomaterial and Technologies. 